\title{
¿HACIA DÓNDE VA LA UNIVERSIDAD? PINCELADAS
}

\author{
Prof. Dr. Luis Espada Recarey \\ Universidad de Vigo
}

Recientemente, se ha definido la Universidad como una institución autónoma que, de modo crítico, produce y transmite la cultura por medio de la investigación y la enseñanza cuya práctica se basa en los valores de independencia moral y científica frente a cualquier poder público.

Sin embargo, no es hasta el siglo XIX cuando se plantean las bases de una Universidad libre respecto a la docencia, el aprendizaje y la investigación, de acuerdo con unos principios más racionales que empíricos.

A lo largo del siglo XX y ya centrándonos en España, la Universidad pasó por varias etapas: desde la subordinación al Estado cuando predominaba una concepción elitista de la cultura superior, hasta alcanzar una autonomía plena y, en algunos casos, una estructura masificada de la enseñanza. La autonomía, recogida en el artículo 27.10 de la Constitución y desarrollada posteriormente en leyes, tiene como finalidad la defensa de la libertad de enseñanza, de investigación y de estudio, y es ejercida mediante una estructura de poder colegial de gran participación representativa y directa. De este modo, la autonomía se interpreta como la capacidad de acción e iniciativa de la institución y como una obligación de rendir cuentas a los agentes sociales que la sustentan. Ello no impide que la Universidad, como consecuencia de su autonomía, tenga una gran capacidad de autogestión y, por tanto, la posibilidad de actuar libremente sobre decisiones que afectan a su futuro dentro de las normas que la sociedad civil, a través de sus representantes elegidos, le imponga.

Nadie duda de que la Universidad es una institución al servicio público, además de ser también un factor de transformación y progreso social. Y también es cierto que debe adaptarse a las necesidades de la sociedad en la que se integra, la cual está en continuo movimiento ya que ésta se estancaría sin los necesarios estímulos de cambio. Con la entrada de España en la Unión Europea, sus universidades se vieron condicionadas a una inevitable puesta a punto, no siempre lograda, conforme a las directrices que algunos países miembros comunitarios aconsejaban, pues el verdadero progreso consiste en renovarse continua y 
paulatinamente. La institución universitaria se ha ido consolidando poco a poco. Tiene defectos, pero también muchas virtudes y son muchos, presentes y ausentes, los que trabaja para mejorar sus estructuras. No hay fórmulas mágicas. Solo sirve el método de la discusión y el análisis de las situaciones y problemas concretos que surjan, realizados con criterios constructivos.

El 25 de mayo de 1998 se reunieron en la Universidad de la Sorbona (París) los ministros de Educación de Francia, Reino Unido, Italia y Alemania. En la conocida como Declaración de la Sorbona recalcaban la intención de que, "siempre respetando nuestra diversidad", se puedan establecer comparaciones y equivalencias de títulos académicos exclusivamente en cuanto a propósitos profesionales.

El 19 de junio de 1999, los ministros de Educación de 29 países europeos firmaron en Bolonia una declaración con tres objetivos fundamentales: 1) que las universidades europeas adquieran un grado de atracción mundial; 2) que se adopte un sistema de titulaciones fácilmente comprensible y comparable; 3) que se ponga en marcha un sistema universitario basado esencialmente en dos ciclos. El 19 de septiembre de ese año, en Berlín, fueron ya 40 los países adheridos al Espacio Europeo de Educación Superior los que enfatizaron la importancia de facilitar la movilidad de estudiantes e investigadores de modo que se crearan los mecanismos para reconocer los títulos y grados alcanzados.

Desde el punto de vista metodológico y operativo, las nuevas estructuras de enseñanza, divididas en áreas de aprendizaje, tendrían como objetivo un contacto más directo entre docentes y estudiantes, la obligatoriedad de la asistencia a las tutorías, una evaluación continuada, una mayor y más cualificada dedicación del profesorado a la docencia y el empleo de un nuevo crédito europeo (ECTS, European Credit Transfer System) que comprende horas de estudio, biblioteca, seminarios, etc. empleadas por el alumnado.

Si pudiéramos concretar, de forma sucinta, una solución a todos los problemas planteados, ésta tendría que pasar forzosamente por el profesorado, pues ahí reside la esencia transformadora de cualquier Universidad. No existe una ecuación matemática que defina y relacione de modo directo el binomio Universidad-Calidad. Sin embargo, cualquier solución a esa ecuación lleva implícito un factor determinante: el profesorado.

En mi opinión, y sin que pretenda tener el don exclusivo sobre la interpretación de la palabra universidad ni mucho menos imponérsela a nadie, la Universidad es para mi guía y norte de mi vida académica y está formada, en líneas generales, por un excelente plantel de profesores. 
Goethe decía que lo que importa no es lo que brilla sino aquello que lo hace brillar. Así pues, una Universidad es buena si tiene un buen profesorado y, por el contrario, no alcanzará la excelencia de su docencia e investigación si su profesorado no es el adecuado.

Cuando miraba a la España de su tiempo, Antonio Machado decía que "El hoy no es bueno, pero el mañana es mío", y nuestro admirado Ortega manifestaba “Que el pasado no tiene sentido más que en función del presente y éste no tiene sentido más que en función del futuro porque la vida es una operación que se hace hacia delante, se vive en el porvenir porque vivir consiste inexorablemente en un hacer". Con esta idea, por la conquista de ese ideal transformador, se requiere trabajar más y mejor, pues es muy poderoso el yo quiero de la voluntad en la consecución de esta victoria. No hay otra alternativa. No tiene futuro una Universidad si no ofrece calidad, pues, en caso contrario, será desplazada por otras.

Este esfuerzo conjunto, que hoy mantenemos entre todos para la consecución de una calidad competitiva, es igual que una batalla, larga quizá, que ganaremos porque en las batallas, y ésta lo es, sólo huyen los vencidos. 